\title{
SOME NEW HARDY-TYPE INEQUALITIES IN $q$-ANALYSIS
}

\section{A. O. Baiarystanov, L. E. Persson, S. Shaimardan and A. Temirkhanova}

Abstract. We derive necessary and sufficient conditions (of Muckenhoupt-Bradley type) for the validity of $q$-analogs of $(r, p)$-weighted Hardy-type inequalities for all possible positive values of the parameters $r$ and $p$. We also point out some possibilities to further develop the theory of Hardy-type inequalities in this new direction.

Mathematics subject classification (2010): 26D10, 26D15, 33D05, 39A13.

Keywords and phrases: Inequalities, Hardy-type inequalities, Riemann-Liouville operator, integral operator, $q$-analysis, $q$-analog, weights.

\section{REFERENCES}

[1] G. A. Anastassiou, Intelligent mathematics: computational analysis Intelligent Systems Reference Library 5, Berlin, Springer, 2011.

[2] K. F. ANDERSEN AND H. P. Heinig, Weighted norm inequalities for certain integral operators, SIAM J. Math. 14 (1983), 834-844.

[3] M. H. AnNABy And Z. S. Mansour, q-fractional calculus and equations, Springer, Heidelberg, 2012.

[4] A. O. Baiarystanov, S. Shaimardan and A. Temirkhanova, Weighted Hardy inequalities in quantum analysis, Vestinik KarGU, Mathematics series, 2013, no. 2 (70), 35-45, (in Russian).

[5] G. BangereZako, Variational calculus on q-nonuniform lattices, J. Math. Anal. Appl. 306 (2005), no. $1,161-179$.

[6] G. Bennett, Some elementary inequalities, Quart. J. Math. Oxford Ser. (2) 38 (1987), no. 152, 401425.

[7] G. Bennett, Some elementary inequalities III, Quart. J. Math. Oxford Ser. (2) 42 (1991), no. 166, $149-174$.

[8] G. BenNetT, Inequalities complimentary to Hardy, Quart. J. Math. Oxford Ser. (2) 49, (1998), 395 432.

[9] J. S. BRadley, Hardy inequalities with mixed norms, Canad. Math. Bull. 21 (1978), 405-408.

[10] M. S. Braverman And V. D. Stepanov, On the discrete Hardy inequality, Bull. London Math. Soc. 26 (1994), no. 3, 283-287.

[11] P. Cheung And V. KaC, Quantum calculus, Edwards Brothers, Inc., Ann Arbor, MI, USA, 2000.

[12] T. ERNST, A comprehensive treatment of q-calculus, Birkhäuser/Springer Basel AG, Basel, 2012.

[13] T. ERNST, The history of $q$-calculus and a new method, Licentiate thesis, Uppsala university, 2001.

[14] H. ExTon, q-Hypergeometric Functions and Applications, Halstead Press, New York, 1983.

[15] H. Gauchman, Integral inequalities in q-calculus, Comput. Math. Appl. 47 (2004), no. 2-3, 281300.

[16] K.-G. Grosse-Erdmann, The Blocking Technique, Weighted Mean Operators and Hardy's Inequality, Lecture Notes in Mathematics, Springer Verlag, Berlin, Germany, 1998.

[17] G. H. HARDY, Note on a theorem of Hilbert, Math. Z. 6 (1920), 314-317.

[18] G. H. HARDY, Notes on some points in the integral calculus. LX. An inequality between integrals, Messenger of Math. 54 (1925), 150-156.

[19] G. H. Hardy and J. E. Littlewood and G. Pólya, Inequalities. Cambridge Mathematical Library, Cambridge University Press, Cambridge, 1934.

[20] F. H. JaCKSON, On q-definite integrals, Quart. J. Pure Appl. Math. 41 (1910), 193-203. 
[21] V. KokilashVili, A. Meskhi And L.-E. Persson, Weighted Norm Inequalities for Integral Transforms with Product Kernels, Nova Science Publishers, New York, 2010.

[22] V. KRASNIQI, Erratum, Several q-integral inequalities, J. Math. Inequal. 5 (2011), no. 3, 451 (Erratum to a paper in J. Math. Inequal. 3 (2009), no. 1, 115-212).

[23] A. Kufner, L. Maligranda And L.-E. Persson, The Hardy Inequality. About its History and Some Related Results, Vydavatelský Servis, Plzen̂, 2007.

[24] A. Kufner And L.-E. Persson, Weighted inequalities of Hardy Type, World Scientific Publishing Co., Inc., River Edge, NJ, 2003.

[25] A. Kufner, L.-E. Persson And N. Samko, Some new scales of weight characterizations of Hardy-type inequalities, Operator theory, pseudo-differential equations and mathematical physics, 261-274, Oper. Theory Adv. Appl., 228, Birkhäuser/Springer, Basel AG, Basel, 2013.

[26] L. Maligranda, R. Oinarov and L.-E. Persson, On Hardy q-inequalities, Czechoslovak Math. J., 64 (2014), no. 3, 659-682.

[27] Y. Miao AND F. QI, Several q-integral inequalities, J. Math. Inequal. 3 (2009), no. 1, 115-121.

[28] B. Muckenhoupt, Hardy's inequality with weights, Studia Math. 44 (1972), 31-38.

[29] C. A. OK Poti, L.-E. Persson AND A. Wedestig, Scales of weight characterizations for the discrete Hardy and Carleman type inequalities, In: Proc. Conf. "Function spaces, Differential operators and Nonlinear Analysis", FSDONA 2004 (Milovy, May 28-Jun 2, 2004), Math. Inst. Acad. Sci. Chech Republic, Prague 2005, 236-258.

[30] L.-E. PERSSON AND V. D. StePanov, Weighted integral inequalities with the geometric mean operator, J. Inequal. Appl., 7 (5): 727-746, 2002.

[31] L.-E. Persson, V. D. Stepanov and P. Wall, Some scales of equivalent chrarcterizations of Hardy's inequal: the case $q<p$, Math. Inequal. Appl. 10 (2007), no. 2, 267-279.

[32] M. S. Stanković, P. M. Rajković And S. D. Marinković, On q-fractional derivatives of Riemann-Liouville and Caputo type, arXiv:0909.0387.

[33] W. T. Sulaiman, New types of q-integral inequalities, Adv. Pure Math. 1 (2011), 77-80.

[34] G. Tomaselli, A class of inequalities, Boll. Un. Mat. Ital. 2 (1969), 622-631. 